\title{
Musical Approach to Auditory Processing Disorder and Phonological Difficulties
}

\author{
Rabih Joseph Nabhan, Michelle Pierre EL Bitar \\ Holy Spirit University of Kaslik (USEK), Kaslik, Lebanon \\ Email: rabihnabhan@usek.edu.lb
}

How to cite this paper: Nabhan, R. J., \& EL Bitar, M. P. (2018). Musical Approach to Auditory Processing Disorder and Phonological Difficulties. Open Journal of Modern Linguistics, 8, 48-53. https://doi.org/10.4236/ojml.2018.83006

Received: April 30, 2018

Accepted: June 22, 2018

Published: June 26, 2018

Copyright $\odot 2018$ by authors and Scientific Research Publishing Inc. This work is licensed under the Creative Commons Attribution International License (CC BY 4.0).

http://creativecommons.org/licenses/by/4.0/

(c) (i) Open Access

\begin{abstract}
Auditory Processing Disorder (APD) is a Learning Disability (LD) that many Lebanese learners suffer from. What is needed is a method that can be implemented in schools as part of the curriculum. A musical approach can help diminish this deficit. This research aims at finding and implementing a constructive musical learning environment that could be of help to those students in order to break the barriers between them and proper education. Lebanese students with APD suffer from lack of awareness toward their particular situation. Instead of being given proper assistance without discriminating them from other students, they are treated either the same as learners without LD or in a manner that makes it hard for them to fit in with their classmates. The purpose of this paper is to examine the positive effect of the musical approach that could be of help to students with APD in Lebanon, so as to work with their phonological difficulties and prevent it from being an impediment in their learning process.
\end{abstract}

\section{Keywords}

Learning Difficulties, Phonology, Auditory Processing Disorder, Musical Approach, Lebanese Educational System

\section{Definition of Terms}

Dyslexia is a reading disorder that is often neurologically-based in that it is grounded in the nervous system. Students face difficulties interpreting words, letters, and symbols. Usually the sound deficiency is in phonology (speech sounds) and phonemes, which are the distinct units of sounds. Therefore, neurology plays a significant factor in the dyslexia problem.

Here arises neuroscientific analysis which comes from "neuroscience" which is a life science branch dealing with the anatomy, physiology, biochemistry, or 
molecular biology of nerves and nervous tissues and especially with their relation to behavior and learning.

Neural encoding is the study of neurons and how they represent information with electrical activity.

Brainstem is the part of the brain connecting the spinal cord with the forebrain and cerebrum.

\section{Introduction to Musical Approach to Auditory Processing Disorder and Phonological Difficulties}

It is common to know that some learners face problems in classrooms because of a learning difficulty they are yet to become familiar with, or because they are not getting the proper education they deserve. Learning difficulties vary from one learner to another, in nature and consequence, according to the environment that surrounds that learner. The Learning Disabilities Association of America describes it as "neurologically-based processing problems. These processing problems can interfere with learning basic skills such as reading, writing and/or math. They can also interfere with higher level skills such as organization, time planning, abstract reasoning, long or short-term memory and attention" (LDA, 2017). Some of the LD might be related to language-based processing skills such as dyslexia and others to how the sounds are interpreted by the brain such as APD (Auditory Processing Disorder). Many of LD could be related to the linguistic fields, in particular, phonology. Auditory Processing Disorder is mainly related to complications students face when it comes to phonological sounds (LDA, 2017).

A constructive learning environment could assist students to deal with those barriers, if not to completely be rid of the source of the problem seeing that sometimes it is biological. In Lebanon particularly, several types of research were conducted in order to find solutions for such issues, in addition to a certain number of centers specialized in supporting LD learners such as the Lebanese Center for Special Education (http://cles.org/) founded in 1999. However, Lebanese students with APD suffer from lack of awareness by the educational system because this system does not train educators to understand the nature of APD so that they can send their students to such centers. In fact, the educational system does not target students with learning difficulties such as APD but leave it to the schools to decide upon what is to be done. Most schools lack the will and the tools to tackle this problem and therefore, a lot of learners with LD are not even recognized. Centers for special education could be more efficient if APD more students were inspected and sent to be treated there. In 2016, "Education Minister Elias Bou Saab Friday announced plans to build 60 schools over the next two years that will cater to children with learning disabilities" (Daily Star, 2016). However, that aim is yet to be achieved. Instead of being given the proper assistance without discriminating them from other students, they are treated either the same as learners without LD or in a manner that makes it hard for them to fit in with other classmates. 
The purpose of this paper is to examine one of the approaches that could be of help to students with APD in Lebanon, in order to work with their phonological difficulties so as it wouldn't be an impediment in their learning process. The approach chosen as a ladder that allows students to get over the barrier is the musical approach. This approach focuses on implementing music lessons and programs in classrooms. To put this approach into action, the Lebanese curriculum must adopt it and enforce it in educational institutions. It can be applied to any class program from grade 1 to grade 12 .

\section{Literature Review}

Phonological awareness is the ability to understand that oral language can be divided into small components and could be manipulated in several ways (Chard \& Dickson, 1999). "The term phonological awareness refers to a general appreciation of the sounds of speech as distinct from their meaning. When that insight includes an understanding that words can be divided into a sequence of phonemes, this finer-grained sensitivity is termed phonemic awareness" (Snow, Burns, \& Griffin, 1998: p. 51).

Learners with Auditory Processing Disorder as defined by the LDAA "do not recognize subtle differences between sounds in words, even when the sounds are loud and clear enough to be heard. They can also find it difficult to tell where sounds are coming from, to make sense of the order of sounds, or to block out competing background noises" (2017). APD can be described as "what the brain does with what the ear hears" (Florida Department of Education, 2001: p. 2). Auditory processing provides auditory abilities that are fundamental to listening and communication (Listen and Learn Center, 2010: p. 1). According to LDAA, people with APD "may process thoughts and ideas slowly and have difficulty explaining them, misspells and mispronounces similar-sounding words or omits syllables; confuses similar-sounding words (celery/salary; belt/built; three/free; jab/job; bash/batch), may be confused by figurative language (metaphor, similes) or misunderstand puns and jokes; interprets words too literally, often are distracted by background sounds/noises". However, the most important aspect of APD for the purpose of this paper is the "difficulty in processing and remembering language-related tasks but no trouble interpreting or recalling non-verbal environmental sounds, music, etc."

Much research was done on the relation between Auditory Processing Disorder, phonological awareness, and music. Seeing that some of the latest research suggested that some of the auditory analysis skills used in the processing of language are parallel to skills necessary for music perception (Lamb \& Gregory, 1993), music can be linked to phonological awareness. Sima H. Anvari, Laurel J. Trainor, Jennifer Woodside, and Betty Ann Levy conducted a study in 2002 where they examined the connection between phonological awareness, music perception skills, and early reading skills. Their participants were a hundred of 4- and 5-year-old children. In the process, they observed that music 
skills are greatly linked to phonological awareness and reading development. The participants took a series of phonemic awareness tasks, reading and vocabulary tasks, as well as music tasks. They suggested that phonological awareness and musical perception might share the same auditory mechanisms because they found out from the children's scores that poor readers had difficulties in differentiating tones in music. In addition, Patel (2012) explains in his paper that some of the latest neuroscientific research explains that musically trained individuals display greater "neural encoding of speech sounds in the auditory brainstem relative to musically untrained individuals" which could be caused by the "innate differences in the structure and function of the auditory system between those who pursue versus who do not pursue musical training" (Patel, 2012).

\section{Solutions}

Similar to other learning difficulties, APD is studied by researchers in order to understand the source of the difficulty and its effect on the learners' performance in and outside the classroom. Bellis (2006) explains that there is no straightforward cure method for APD and its treatment "must be highly individualized". Suggested treatments in the literature are not generalized and could work for one child and not with the other. He suggests that "treatment of APD generally focuses on three primary areas: changing the learning or communication environment, recruiting higher-order skills to help compensate for the disorder, and remediation of the auditory deficit itself". Environmental modification is vital to facilitate the process of accessing the information given to the learners by their auditory system. Compensatory strategies are suggestions given to the listeners in order to strengthen their cognitive skills and hence overcome the auditory disorder. Remediating auditory processing itself comes with several treatment activities such as computer-based activities or one-on-one meetings with specialized therapists.

Understood, a team of experts who create thousands of articles to help parents during the process of assisting their children in their education, explains that speech therapy could help with reading and language comprehension. Morin (2014) states that there is no medication that would remove the difficulties or help the students get over their APD. Auditory training therapy is also beneficial for it includes programs such as Berard Auditory Integration Training Services and Fast ForWord; their goal is to improve listening comprehension by using numerous related activities and games.

\section{Suggestions}

From the review of the literature, it is evident that music is rarely being used in the therapy related to Auditory Processing Disorder. Its role in the improvement of the phonological awareness within the learners with this difficulty is vital and should not be disregarded. Therefore, music classes should be added to the Le- 
banese curriculum until the end of school years and even in higher education programs. Schools are to assign a 50-minute period every week for music classes at all levels. With research and experiments, appropriate music lessons and programs can be adopted to tackle each level taking into consideration the APD deficit that some students might suffer from. In other words, the music therapy could be on-going every year and thus this continuity could serve as a remediation for any phonological deficiency. The music lessons could be entertaining for all learners and at the same time could tackle every phonemic deficit within any student. It cannot happen within a short time but as mentioned earlier it is continuous starting from first grade to final school grade.

Every school should have a testing program for students who display symptoms of APD. If the feedback on the existence of the disorder is a positive one, the students should be given more musical classes. In that manner, they would not be discriminated inside the class so as to feel alienated and different from their classmates and at the same time, they would benefit from a musical program that is both fun and beneficial to them. In addition, specific programs that can tackle the phoneme deficits should be designed by experts in music and phonology. Class levels should be considered like any other educational programs.

Mary Luehrisen, executive director of the National Association of Music Merchants (NAMM), says that "When you look at children aged two to nine, one of the breakthroughs in that area is music's benefit for language development, which is so important at that stage. Growing up in a musically rich environment is often advantageous for children's language development." She also adds that inborn capacities should be "reinforced, practiced, celebrated," which is done in a more formal music education setting (Brown, 2012).

Finally, it is recommended that further research be conducted to track the changes with students suffering from APD with the focus on musical treatment in order to test its efficacy.

\section{References}

Bellis, T. J. (2006). Understanding Auditory Processing Disorders in Children. https://www.asha.org/public/hearing/Understanding-Auditory-Processing-Disorders-i n-Children/

Brown, L. L. (2012). The Benefits of Music Education. http://www.pbs.org/parents/education/music-arts/the-benefits-of-music-education/

Chard, D. J., \& Dickson, S. V. (1999). Phonological Awareness. Intervention in School and Clinic, 34, 261-270. https://doi.org/10.1177/105345129903400502

Daily Star (2016). Students with Learning Disabilities to Get to Schools. http://www.dailystar.com.lb/News/Lebanon-News/2016/Apr-23/348842-students-withl earning-disabilities-to-getschools.ashx

Florida Department of Education (2001). Technical Assistance Paper: Auditory Processing Disorders, No. 10967. Florida: Author.

LDA (2017). Types of Learning Disabilities. https://ldaamerica.org/types-of-learning-disabilities/ 
Listen and Learn Center (2010). Auditory Processing Disorder and Reading Difficulties.

Morin, A. (2014). Treatment Options for Auditory Processing Disorder.

https://www.understood.org/en/learning-attention-issues/treatments-approaches/treat ment-options/treatment-options-for-auditory-processing-disorder

Patel, A. D. (2012). The OPERA Hypothesis: Assumptions and Clarifications. Annals of the New York Academy of Sciences, 1252, 124-128.

https://doi.org/10.1111/j.1749-6632.2011.06426.x

Snow, C. E., Burns, M. S., \& Griffin, P (1998). Preventing Reading Difficulties in Young Children. Washington DC: National Academy Press. 